Tesis. Año 13, 12(14), 2019, 171-194

\title{
Breve reflexión sobre la vida de cinco filósofos griegos a partir del término resiliencia
}

\author{
Luis Alberto Bretoneche Gutiérrez \\ labguni218@gmail.com
}

\section{Resumen}

En este breve artículo se analiza el término resiliencia desde su origen o significado etimológico y las contradicciones que esto acarrea hasta su aplicación en varias disciplinas científicas como la física, psicología y educación. Luego, considerando estos antecedentes, se examina de manera libre la aplicación de este concepto a la enseñanza de la filosofía. Con este espíritu, se presentan cinco ejemplos de vida donde se aplican libremente los significados de resiliencia. Esta aplicación se realiza con la finalidad de que este tema se convierta en un aporte a la filosofía, principalmente en la motivación de su enseñanza. De este modo, se define a la resiliencia como la motivación que tienen las personas para seguir sus sueños y proyectos de vida a pesar de pasar por situaciones difíciles o extremas, tomando como ejemplos la vida de Tales de Mileto, Sócrates, Platón, Aristóteles y Cleantes.

Palabras clave: Resiliencia, resiliencia y educación, resiliencia y filosofía, resiliencia y motivación, resiliencia y psicología.

\begin{abstract}
In this short article the term resilience is analyzed from its origin or etymological meaning and the contradictions that this leads to its application in several scientific disciplines such as physics, psychology and education. Then, considering these antecedents, the application of this concept to the teaching of philosophy is examined in a free way. In this spirit, five life examples are presented where the meanings of resilience are freely applied. This application is made with the purpose that this topic becomes a contribution to philosophy, mainly in the motivation of teaching. In this way, resilience is defined as the motivation that people have to follow their dreams and life projects despite going through difficult or extreme situations, taking as examples the life of Thales of Miletus, Socrates, Plato, Aristotle and Cleantes.
\end{abstract}

Keywords: Resilience, resilience and education, resilience and philosophy, resilience and motivation, resilience and psychology. 


\section{Breve reflexión sobre la vida de cinco filósofos griegos a partir del término resiliencia}

\section{Introducción}

En este texto se emplea un método interpretativo y de análisis conceptual para el estudio del tema en cuestión: la resiliencia. El objetivo que se tiene es esclarecer el empleo del concepto de resiliencia en diversas disciplinas y proponer que este uso se puede dar, también, en la filosofía. Para ello, primero se explorará de manera panorámica los diversos usos que se dan o se le pueden dar al término en la física, ciencias sociales, psicología, educación y, por supuesto, en la filosofía; luego, se examinará la utilidad que se le puede dar al término resiliencia en la filosofía para incentivar la motivación en el estudio de esta disciplina; tercero, se darán cinco ejemplos de conceptos afines a la resiliencia o con los cuales se explica mejor el término en la vida y obra de cinco filósofos griegos y, por último, se finalizará señalando las conclusiones de la investigación.

\section{Origen y contradicciones del empleo del término resiliencia}

Es evidente que el concepto de resiliencia se ha puesto de moda, actualmente, en el mundo académico como un tema de análisis, reflexión, debate y aplicación entre los psicólogos, por un lado, y educadores, por el otro. Este término que proviene del verbo latino resilǐo, resilŭi, resultum que significa "saltar atrás, replegarse; rebotar y retirarse" (Diccionario latino-español español-latino, 1958, p. 359), se utilizó en el área disciplinar de la física para luego ser empleado en el terreno social, psicológico y educativo. Un resumen breve de este traslado multidisciplinar y cambio de significado del vocablo se encuentra en las siguientes palabras:

En los últimos años ha surgido en la psicología un concepto que pretende explicar la capacidad natural que tienen las personas para crecer óptimamente en medio de la adversidad. Este concepto denominado resiliencia ha sido tomado prestado de la física, donde el término hace 
referencia a la propiedad de algunos metales de volver a su estado natural luego de haber sido sometida a duras presiones. La resiliencia originalmente fue definida como la capacidad de recuperar rápidamente la condición psicosocial después de haber sido forzado, lastimado o presionado; el concepto fue enunciado por Rutter M. (1987) quien observó que niños criados en situaciones de alto riesgo, desarrollaban un buen ajuste psicosocial logrando ser adultos competentes. En la actualidad las investigaciones sobre el tema dan posibilidades a nuevas interpretaciones del concepto así como nuevas ideas respecto a su naturaleza. Una aproximación conceptual de la resiliencia desde una perspectiva del desarrollo humano nos señalaría que la misma sería una capacidad natural de las personas para resistir, afrontar y superar condiciones de riesgo y situaciones adversas desde períodos muy tempranos del desarrollo. (Benites, 2001, p. 21)

Es así, entonces, cómo la palabra resiliencia fue introducida a la psicología por el psiquiatra Michael Rutter. Este término fue utilizado tambié, por el etólogo Boris Cyrulnik en su libro Los patitos feos y en su artículo "Comment un professionnel peut-il devenir un tuteur de résilience?” que aparece en el libro La résilience ou comment renaître de sa souffrance, el cual fuera publicado en dirección conjunta con Claude Seron, y en donde expresa que la resiliencia es un renacer del sufrimiento.

Por otro lado, en el texto Los Patitos feo, Boris Cyrulnik afirma tres cosas importantes: la primera, cuando cuenta la historia del niño Pero, en Zagreb, el cual se adaptaba fácilmente a circunstancias adversas: "El distanciamiento llegó a ser para el niño una necesidad adaptativa" (Cyrulnik, 2005, p. 143). Sin embargo, acerca de ese comportamiento, el autor no lo recomienda y llega a afirma que: "Contrariamente a lo que se piensa, una adaptación excesivamente buena no es una prueba de resiliencia, e incluso ocurre que una culpabilidad torturadora organiza estrategias de existencia resilientes" (Cyrulnik, p. 141). Todo esto lo llevó a sostener al inicio de su libro que la resiliencia es: "esa capacidad de soportar el golpe y restablecer un desarrollo en unas circunstancias adversas" (Cyrulnik, p. 26), y a recomendar el trabajo en tres planos para curar las heridas que provocan el trauma. Esta relación entre resiliencia y trauma, sobre todo un trauma psíquico, volverá a aparecer en la conclusión del texto, donde el escritor señalará la necesidad del primer concepto para "la prevención de los traumas y a su mejor reparación" (Cyrulnik, p. 212).

A lo mencionado, hay que añadir la propuesta de los factores protectores o pilares de la resiliencia que ayudan al ser humano a enfrentar y superar la adversidad, estos son los siguientes: autoestima consistente, introspección, independencia, capacidad de relacionarse, iniciativa, humor, creatividad, moralidad y capacidad de pensamiento crítico (Melillo, 2004). Con respecto a esta retahíla 
de conceptos con los que podemos explicar a la resiliencia, se puede aumentar parte de la compilación de significados que hacen otros investigadores:

Habilidad para surgir de la adversidad, adaptarse, recuperarse y acceder a una vida significativa y productiva.

Historia de adaptaciones exitosas en el individuo que se ha visto expuesto a factores biológicos de riesgo o eventos de vida estresantes...

Enfrentamiento efectivo ante eventos y circunstancias de la vida severamente estresantes y acumulativos.

Capacidad humana universal de hacer frente a las adversidades de la vida, superarlas o incluso ser transformado por ellas...

La resiliencia habla de una combinación de factores que permiten a un niño, a un ser humano, afrontar y superar los problemas y adversidades de la vida.

La resiliencia se ha caracterizado como un conjunto de procesos sociales e intrapsíquicos que posibilitan una vida sana, viviendo en un medio insano... (Kotliarenco, Cáceres y Fontecilla, 1997, pp. 5 y 6)

Hasta lo avanzado, se ha hecho alusión al sentido positivo de la resiliencia, donde se han realizado diferentes listados del significado positivo de resiliencia en diferentes autores; sin embargo, esto no es el único sentido que tiene el término analizado, sino que también existe el sentido negativo, como se verá a continuación.

Por otro lado, en un artículo en el cual se analiza de manera crítica el concepto de resiliencia en la psicología y se hace, a la vez, un estudio de Ribes donde se señalan dos usos del lenguaje: el ordinario y el técnico. Se sostiene que el primero tiene relación con el "sentir y el hacer", mientras que el segundo tiene correspondencia con el "describir y designar" (Piña, p. 751).- Además, posee otras características: "en el lenguaje técnico son unívocos y tienen un único significado" (Piña, p. 751). Esto va a llevar al autor a afirmar que "un psicólogo no puede tomar prestados los términos del lenguaje ordinario" (Piña, p. 751) - siendo este el caso de la resiliencia - porque, aunque no lo diga, queda claro por los antecedentes descritos, el empleo de este término en la psicología pertenecería a la esfera del uso equívoco del lenguaje, es decir, queda en la posibilidad de tener muchos significados, como a continuación se señalará:

De hecho, el lector podrá constatar que el de resiliencia ha adquirido un estatuto especial como una especie de concepto comodín y multiusos, al que inclusive se le confunde con otros conceptos o expresiones, como los de empatía, sentido del humor, afrontamiento, autoeficacia, 
perseverancia, competencia, religiosidad, optimismo, tenacidad, control personal, personalidad 'resistente', etcétera. (Piña, 2015, p.751)

Como se ha observado, el autor es un crítico furibundo del uso del término resiliencia en la psicología porque es un término recogido del lenguaje ordinario, como el de malnutrición psicológica, que tiene muchos significados y que, por lo tanto, "es ajeno a la propia psicología" (Piña, 2015, p. 757). Esta sería la crítica al sentido positivo del término resiliencia y constituiría, por ende, el sentido negativo.

Aclarado entonces de que el constructo o concepto de resiliencia sea usado en la psicología en el sentido positivo - cuando se emplea como lenguaje técnico, según el trabajo de Julio Piña - o el sentido negativo — cuando pertenece a la esfera del lenguaje ordinario que forzadamente se le utiliza como técnico en la disciplina mencionada-, el manejo de este término es aceptado por algunas comunidades profesionales o científicas por un lado, pero por el otro, por el contrario, esto no es admitido por algunos representantes y estudiosos de este gremio profesional, los cuales identifican el uso ordinario de este concepto como no profesional ni científico; es decir, le darían un sentido negativo y, por ende, teniendo en cuenta las tesis de unos y otros, se puede notar que resiliencia es un término que implica muchas cosas que tienen algo en común: la posibilidad de personas para superar situaciones límites en sus vivencias, conflictos, adversidades, crisis, adaptaciones y derrotas o problemas de todo tipo - materiales, espirituales, sentimentales, económicas, existenciales, etcétera- para, luego, salir triunfantes o exitosos.

Desde la perspectiva expuesta y aceptando o no la definición técnica del término resiliencia, se puede observar que en la historia de la filosofía hay casos de algunos filósofos a los cuales se les puede atribuir casos de resiliencia por la forma que afrontaron las adversidades que se les presentaron. Una aclaración necesaria al respecto es que si bien se puede considerar incompatible observar o estudiar la vida y el pensamiento de los personajes antiguos o históricos a la luz de teorías y conceptos modernos o contemporáneos, por el contrario, aquí se hace esta relación con la licencia respectiva porque - a pesar de ser ambiguo el término y, también, se puede percibir que tiene relación con todos los seres humanos en todas las épocas y no solo cuando se empieza hablar de él por la tarea emprendida por Boris Cyrulnik - se considera que es factible aplicar el término en mención a la vida de cualquier protagonista en cualquier época porque los múltiples significados que este neologismo tiene así lo permiten y, además, aparecen como características adicionales en la vida de muchos personajes. 


\section{La resiliencia en la enseñanza de la filosofía}

De todo lo desarrollado, se puede inferir que el término resiliencia sirve en el ámbito social, psicológico y educativo para explicar la conducta de las personas que tienen la capacidad de salir de la adversidad, superar todo tipo de escollos y triunfar a pesar de las circunstancias negativas que hay en su entorno. Dar ejemplos de esta actitud puede servir - y sirve- para las tareas terapéuticas de los profesionales de la salud mental, de la conducta y de la educación; pero ¿qué utilidad puede tener este concepto para la filosofía? En este nuevo escenario del uso social y personal del término parece que los profesionales del quehacer filosófico no tuvieran nada que decir, sin embargo, si se realiza una reflexión sobre el término y tomándose algunas licencias, se puede observar la pertinencia de la expresión con este quehacer. Por ejemplo, la resiliencia se puede presentar en la enseñanza para explicar a los estudiantes que hubo filósofos que hicieron todo lo posible para superar las circunstancias adversas que los rodeaban y siguieron haciendo lo que más les gustaba realizar: pensar, filosofar, ayudar a pensar o enseñar a filosofar; es decir, se puede presentar el término como la capacidad del ser humano - en este caso, del filósofo- para enfrentar situaciones adversas en su vida y salir adelante a pesar de las dificultades encontradas hasta realizar su proyecto de vida. En otras palabras, ante la pregunta ya planteada, surge aquí la respuesta: el sentido de reflexionar sobre la resiliencia en el campo filosófico puede hacer que en los estudiantes se despierte el interés por la filosofía o el filosofar, mediante la motivación.

Aun cuando en los estudiantes universitarios de la especialidad de filosofía no se presenta, por lo general, la falta de motivación para el estudio como un problema en el proceso de enseñanza y aprendizaje de algún curso relacionado con esta disciplina, por otro lado, en los estudiantes que no son de esta especialidad sucede todo lo contrario, ya que en ellos se manifiesta como una dificultad la carencia de estimulación para aprender los contenidos y alcanzar los objetivos de alguna asignatura filosófica o alcanzar las competencias y capacidades señaladas en las mismas. Se presenta, entonces, una interrogante: ¡cómo resolver esta dificultad? Sin duda alguna deben existir muchas formas, procedimientos o métodos didácticos para solucionar este asunto y que los docentes de filosofía pueden conocer y aplicar en el aula, sin embargo, falta socializar estas estrategias didácticas. Con la finalidad de aportar a la enseñanza de la filosofía y contribuir con la comunidad filosófica, de un modo u otro, a solucionar la dificultad mencionada, se presenta, de manera escueta y como una interpretación particular, cinco ejemplos motivadores de resiliencia en la figura y vida de cinco filósofos griegos. Con este espíritu estimulador es que surge ahora la necesidad de aclarar que el objetivo propuesto en este texto no es el de hacer una lectura anacrónica de la vida de algunos personajes de la antigüedad con la aplicación de conceptos actuales, es decir, no se trata de observar o analizar los contextos 
pasados con los conceptos modernos ya que esta acción sería incoherente. La única intención que existe en la elaboración de este escrito es la de tomarse una licencia para hacer una interpretación de la vida de los personajes de la filosofía griega a partir de los significados del término de resiliencia que han elaborado diversos autores, ya que si bien esta noción de resiliencia no fue conocida ni utilizada en ese período de la historia de la filosofía para comprender los actos humanos en situaciones adversas específicas, se considera aquí que las explicaciones, características, definiciones o significados que aparecen de este término son pertinentes y aplicables para comprender ciertos casos que se mencionarán más adelante.

\section{La resiliencia en cinco filósofos griegos de la antigüedad}

Desde la perspectiva señalada, se analizará la vida de cinco representantes de la filosofía griega y se verá la manera cómo estos personajes pudieron sobreponerse a la adversidad para lograr sus objetivos en el campo de la actividad especulativa. En otras palabras, utilizando los significados del término en cuestión, se observarán cinco modelos de resiliencia en la vida de los personajes de la filosofía griega antigua que pueden servir de ejemplo o estímulo a cualquier persona que quiera aprender a filosofar a pesar de encontrarse en circunstancias adversas para ejercer el uso libre de la razón. Estos personajes son Tales de Mileto, Sócrates, Platón, Aristóteles y Cleantes. Se espera, de esta manera, que la narración sobre la vida de estos cinco filósofos contribuya de manera significativa a la historia de la filosofía para que los estudiantes se sientan identificados y motivados en la reflexión de esta disciplina que, por lo general, siempre empieza con información biográfica o contextual.

\section{La resiliencia en Tales de Mileto}

El primer ejemplo que se plantea es el de Tales de Mileto (640-545 antes de n. e.). Según cuenta la anécdota, cuando Tales paseaba por su ciudad natal mirando las estrellas cayó en un foso del cual no pudo salir por sus propios medios, causando la sorna de sus conciudadanos:

Como también se dice que Tales, mientras estudiaba los astros... y miraba hacia arriba, cayó en un pozo, y que una bonita y graciosa criada tracia se burló de que quisiera conocer las cosas del cielo y no advirtiera las que tenía junto a sus pies. (Los filósofos presocráticos, 2001, p. 12)

Ante esta actitud, este filósofo planeó castigar a los burlones apenas pudiera salir de la situación tan bochornosa en la cual se encontraba. Y lo hizo. Es conocida, a través de la historia de la filosofía, su reacción de comprar y alquilar todas las prensas de oliva de su ciudad natal y los lugares aledaños, esto 
lo convirtió en el primer acaparador reconocido de la historia, lo cual le rindió cuantiosos réditos cuando se produjo la cosecha ya que comenzó a especular con los precios de las prensas cuando fueron a comprárselas o alquilárselas:

En efecto, como lo injuriaban por su pobreza y por la inutilidad de la filosofía, se dice que, gracias a sus conocimientos astronómicos, pudo saber cómo sería la cosecha de aceitunas. Así, cuando era aún invierno y tenía un poco de dinero, tomó mediante fianza todas las prensas de aceite de Mileto y de Quíos, arrendándolas por muy poco, pues no había competencia. Cuando llegó la oportunidad y todos a la vez buscaban prensas, las alquiló como quería, juntando mucho dinero, para demostrar que fácil resulta a los filósofos enriquecerse cuando quieren hacerlo. (Los filósofos presocráticos, 2001, pp. 12- 13)

Si bien de esta anécdota se pueden sacar consecuencias negativas sobre la actitud que tuvo Tales de Mileto al responder la burla que hicieran sus paisanos del accidente en el pozo: la venganza, el acaparamiento de bienes o mercancías, la especulación de los precios y el monopolio; también se pueden extraer consecuencias positivas como la enseñanza a los demás acerca de la utilidad práctica que todos pueden obtener del conocimiento y la sabiduría si se lo propusieran, es decir, de la actividad a la que uno se dedica con tesón y sin ningún interés subalterno. Este incidente fue narrado también en la antigüedad por el Peripatético:

Se dice que Thales de Mileto tenía certera visión de los negocios, atribuyéndole un hecho que prueba su prudente sabiduría, que encierra principio de aplicación universal. Un día le reprocharon su pobreza, con el propósito de convencerle de que la filosofía era inútil para él. Se asegura que sus conocimientos astronómicos le sugirieron, estando en invierno, que la cosecha de olivas sería abundante el año próximo; el filósofo empleó el poco dinero que poseía contratando todas las prensas de aceite existentes en Chios y Mileto, mediante reducido precio, pues nadie le disputó la operación. Cuando llegó la recogida de olivas muchos pretendieron hacer uso de las prensas, queriendo ser los primeros; entonces las realquiló a elevadísimos precios, reuniendo inmenso caudal. Con ello demostró que los filósofos pueden enriquecerse con facilidad si quieren, pero su ambición es muy otra. Con dicho relato se pretende probar la sabiduría de Thales, mas, como he indicado ya, su especulación o procedimiento para adquirir riqueza es de aplicación universal: el monopolio. (Aristóteles, 1976, p. 281)

Este suceso fue tan célebre que fue narrado, con la parte jocosa, tanto en tiempos cercanos - por Bertrand Russell, pero citando a Aristóteles-: "Existen muchas leyendas sobre él, si bien no creo se sepan más hechos positivos de los que menciono. Algunas historietas son divertidas, por ejemplo, la que 
cuenta Aristóteles en su Política" (Russell, 1971, p. 46), como en épocas lejanas — por Diógenes de Laercio-:

Gerónimo de Rodas en el segundo libro de sus Notas dispersas relata que, a fin de mostrar que es fácil hacerse rico, Thales, previniendo que sería una buena estación para los olivos, alquiló todos los molinos de olivos y así amasó una fortuna. ${ }^{1}$ (Diogenes Laertius, 1959, p. 27)

En resumen, acerca de Thales de Mileto, podemos afirmar que, a pesar del contexto en que vivió y ser considerado uno de los siete sabios de la antigüedad, su actividad filosófica no fue estimada por sus conciudadanos, pero él supo salir de las circunstancias sociales y económicas que les eran adversas para hacer lo que más estimaba conveniente: filosofar, que en aquel contexto significaba buscar la verdad.

Como un comentario adicional, se puede afirmar que, ante una situación estresante y límite como la que enfrentó Thales de Mileto, él pudo superar la adversidad. En su experiencia se puede observar que la resiliencia aparece como iniciativa y creatividad, según las consideraciones o pilares que señala Melillo (2004), tratando, claro está, de sacar provecho a todas las situaciones en que uno se encuentre.

\section{La resiliencia en Sócrates}

Nadie ignora que en Grecia se despreciaba el trabajo artesanal lo cual no era considerado digno de los hombres libres, por ende, los filósofos debían estar alejados de esta actividad e, incluso, no debían recibir un pago por enseñar. En este contexto surge la figura de Sócrates (470-399 antes de n. e.) versus sus más entrañables rivales: los sofistas.

Acerca del origen humilde de Sócrates, esta historia fue contada por Diógenes de Laercio: "Sócrates fue el hijo de Sofronisco, un escultor, y Fenareta, una partera, como nosotros leemos en el Teeteto de Platón; él fue un ciudadano de Atenas y perteneció al barrio de Alopecea"2 (Diogenes Laertius, 1959, p. 149). Este origen humilde no impidió que Sócrates aprendiera a filosofar y enseñara filosofía, esto último lo realizó sin recibir a cambio pago alguno por su actividad, cosa que lo distinguió profundamente de los sofistas. Sin embargo, no hay que olvidar que fuera del ámbito popular y democrático, Sócrates tuviera otros enemigos provenientes del seno de la aristocracia ateniense, siendo Aristófanes, el padre de la comedia, el más notable de todos ellos.

En Las nubes, por ejemplo, se hace referencia a un Sócrates con el perfil de sofista y alejado de la realidad material. Se percibe que cuando conversa con El Discípulo, le responde al débil mortal: "Camino por los aires. Mi pensamiento incuba el sol” (Aristófanes, 1957, p. 86). O, cuando dialoga con Estrepsíades 
sobre el futuro del hijo de este que está bajo su instrucción, le dice: "Tranquilízate. Volverá a ti hecho un sofista de primera línea” (Aristófanes, p. 106). Esto y todas sus aparentes miserias son corroborados por el Coro de Nubes:

¡Salud, anciano cargado de años, cazador de las conversaciones amadas de las Musas! Y tú, pontífice de las archisutiles necedades, dinos lo que deseas. Tú eres entre todos los nublados sofistas de hoy, junto con Pródico, el único a quien escuchamos. A éste, por su ciencia y su razón, y a ti por tu andar arrogante por las calles, moviendo los ojos majestuosamente, descalzo, sufriendo mil miserias y siempre orgulloso y radiante con nuestro apoyo. (Aristófanes, 1957, p. 89)

En relación a estos escenarios: primero, sobre el origen humilde de Sócrates, lo cual, se supone, lo debió obligar a ganar su sustento con el trabajo y el sudor que esta actividad produce y, por ende, debió alejarlo de la filosofía, y, segundo, con respecto a la crítica de Aristófanes que surge como el adversario y crítico más hostil de la actividad socrática, existe el siguiente comentario:

Era Sócrates de Alopeké, el hijo de un picapedrero y de una comadrona. Tenía la gran ventaja sobre los sofistas, que sólo raramente visitaban Atenas, de ser un original más eficaz en la escena, por ser un conocido de toda la ciudad. El capricho de la naturaleza había cuidado incluso de su máscara cómica dándole aquel aspecto de sileno, con la nariz arremangada, los labios protuberantes y los ojos saltones. Sólo había que exagerar lo grotesco de su figura. Aristófanes amontonó sobre su víctima todas las características de la clase a la que pertenecía: sofistas, retóricos y filósofos de la naturaleza, o, como se decía entonces, meteorólogos. Aunque en realidad se pasaba casi todo el día en el mercado, colocó misteriosamente a su fantástico Sócrates en una estrecha tienda de pensador, donde, suspendido en un columpio en lo alto del patio, "investigaba el sol" con el cuello torcido, mientras sus discípulos, sentados en el suelo, hundían en la arena sus pálidos semblantes para sondear el mundo subterráneo. Se suele considerar a Las nubes desde el punto de vista de la historia de la filosofía y, en el mejor de los casos, se le disculpa... (Jaeger, 2010, p. 336)

Resumiendo lo avanzado, se puede afirmar y repetir, entonces, acerca de la situación social de Sócrates que, aunque hombre libre, Sócrates fue hijo de escultor o picapedrero, $y$, además, de partera o comadrona, lo cual lo califica como un hombre de origen humilde. Sobre el oficio de su madre va a admitir lo siguiente: "Vamos a ver, risible muchacho: ¿no has oído decir que soy hijo de una comadrona llamada Fenareta bien noble e imponente?" (Platón, 1975, p. 24). Por otro lado, en la Apología de Platón, se hace referencia a un deslinde con los sofistas que hace el personaje Sócrates con respecto a la actitud de cobrar por enseñar, lo cual es un aspecto fundamental para diferenciarlo de estos: 
Jamás he tenido por oficio el enseñar, y si ha habido algunos jóvenes o ancianos que han tenido deseo de verme a la obra, oír mis conversaciones, no les he negado esta satisfacción, porque no es mercenario mi oficio, no rehuso el hablar, aun cuando en nada se me retribuye, y estoy dispuesto siempre a franquearme con ricos y pobres, dándoles toda anchura para que me pregunten, y si lo prefieren, para que me respondan a las cuestiones que yo suscite. (Platón, 1965, p. 30)

Hay que recordar aquí que el cobrar por enseñar era una de las características principales, si es que no era la más notable entre las principales, de los sofistas, por ende, era necesario que Platón hiciera este deslinde con Aristófanes a favor de su maestro. En fin, por filosofar, Sócrates fue denunciado, aunque disfrazado con la acusación de corromper a la juventud, ateísmo e impiedad, es

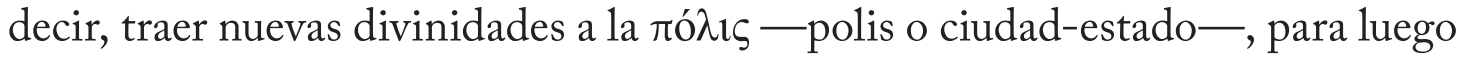
ser llevado a un tribunal:

Pasemos ahora a las últimas, y tratemos de responder a Melito, a este hombre de bien, tan llevado, si hemos de creerle, por el amor a la patria. Repitamos esta última acusación, como hemos enunciado la primera. Hela aquí, poco más o menos: Sócrates es culpable, porque corrompe a los jóvenes, porque no cree en los dioses de Estado y porque en lugar de éstos pone divinidades nuevas bajo el nombre de demonios. (Platón, 1965, p. 18)

Pero, a pesar de estar en una situación crítica frente a la ley de su ciudad-estado, Sócrates hace una declaración comprometedora para su vida y la filosofía. Frente a la opción de ser libre y dejar de filosofar, o morir dignamente haciendo lo que más ama: filosofar, él elige lo segundo:

$\mathrm{Si}$, a pesar de las instancias de Anito, quien ha manifestado, que o no haberme traído ante el tribunal, o que una vez llamado, no podéis vosotros dispensaros de hacerme morir, porque, dice, que si me escapase de la muerte, vuestros hijos, que son ya afectos a la doctrina de Sócrates, serían irremisiblemente corrompidos, me dijeseis: Sócrates, en nada estimamos la acusación de Anito, y te declaramos absuelto, pero es a condición de que cesarás de filosofar y de hacer tus indagaciones acostumbradas, y si reincides, y llega a descubrirse, tú morirás, si me dieseis libertad bajo estas condiciones, os respondería sin dudar: Atenienses, os respeto y os amo; pero obedeceré a Dios antes que a vosotros, y mientras que yo viva, no cesaré de filosofar, dándoos siempre consejos, volviendo a mi vida ordinaria, y diciendo a uno de vosotros cuando os encuentre: Buen hombre, ¿cómo siendo ateniense y ciudadano de la más grande ciudad del mundo por su sabiduría y por su valor, cómo no te avergüenzas de no haber pensado más que en amontonar riquezas, en adquirir créditos y honores, en despreciar los tesoros de la verdad y de la sabiduría, y de no trabajar para hacer tu alma tan buena como pueda serlo? (Platón, 1965, pp. 25 y 26) 
Esta declaración de Sócrates es, por sí sola, una condena a la muerte ya que, aunque ya ha rechazado en otras declaraciones las acusaciones de ateísmo e impiedad, aquí, al afirmar que va a filosofar siempre, está admitiendo tácitamente que va a seguir corrompiendo a la juventud. Esto se puede comprobar cuando, al final Sócrates hace un petitorio a sus juzgadores, de manera irónica, pidiéndoles que hagan a su prole lo que él hizo a los jóvenes de Atenas, es decir, enseñar a filosofar:

No tengo ningún resentimiento contra mis acusadores, ni contra los que me han condenado, aun cuando no haya sido su intención hacerme un bien, sino por el contrario hacerme un mal, lo que sería un motivo para quejarme de ellos. Pero sólo una gracia tengo que pedirles. Cuando mis hijos sean mayores os suplico los hostiguéis, los atormentéis, como yo os he atormentado a vosotros, si veis que prefieren las riquezas a la virtud y que se crean algo cuando no son nada; no dejéis de sacarlos a la vergüenza, si no se aplican a lo que deben aplicarse, y creen ser lo que no son, porque así es como yo he obrado con vosotros. Si me concedéis esta gracia, lo mismo yo que mis hijos no podremos menos de alabar vuestra justicia. Pero ya es tiempo para que nos retiremos de aquí, yo para morir, vosotros para vivir. Entre vosotros y yo, ¿quién lleva la mejor parte? Esto es lo que nadie sabe, excepto el dios. (Platón, 1965, pp. 41 y 42)

En síntesis, se puede inferir de todo lo descrito que Sócrates provino de un hogar sencillo ubicado en un barrio humilde de Atenas: Alopecea y, por lo tanto, se puede aseverar que no nació en cuna de oro sino en un hogar donde todos los miembros de la familia tuvieron que trabajar para obtener los medios necesarios para subsistir. De esto se puede desprender la idea de que, más adelante, él tampoco poseyera los recursos necesarios para fundar una escuela y enseñar a filosofar dentro de ella, sin embargo, tuvo la suficiente entereza para enfrentar esta situación y dedicarse a lo que más quería: enseñar a pensar a sus discípulos en plazas, calles y mercados, y enfrentar a sus enemigos con dignidad y grandeza moral en la adversidad. Además de estos datos biográficos, se puede observar que en Sócrates no existe odio ni maldad ante la situación adversa, solo existe sorna y resignación propios de la conducta resiliente, según Aldo Melillo (2004), y que demuestra que las personas de origen sencillo pueden triunfar a pesar de la adversidad: "Los niños de origen humilde pueden triunfar" (Cyrulnik, 2005, p. 211), pero luchando contra la adversidad: "La resiliencia es el arte de navegar contra la adversidad" (Cyrulnik, p. 213). Además, con respecto a lo aseverado y como se mencionó al principio de este acápite, entre los pilares de la resiliencia, según Melillo (2004), aparece la autoestima, introspección, independencia, capacidad de relacionarse, iniciativa, humor, creatividad, moralidad y capacidad de pensamiento crítico. Todos estos factores protectores para enfrentar la adversidad se ven representados en la vida de Sócrates. 


\section{La resiliencia en Platón}

La figura de Aristocles o Platón (428-347 antes de n. e.), el de los hombros anchos, uno de los discípulos de Sócrates, fue distinta a la de su maestro con respecto a sus orígenes o alcurnia, pero tiene cierta semejanza cuando se observan los riesgos por los que pasaron los dos. Según Diógenes de Laercio, "Platón fue hijo de Aristón y una ciudadana de Atenas. Su madre fue Perictone (o Potone), quien reconstruyó su descendencia hasta Solón”3 (Diogenes Laertius, 1959, p. 277). Luego va a añadir que por línea materna fue descendiente de uno de los treinta tiranos de Atenas.

Acerca de la vida de Platón se destaca que viajó mucho, pero los viajes que interesan para este propósito son las tres navegaciones que realizó a Siracusa, Sicilia. Al respecto, cuenta Diogenes de Laercio que:

Él hizo tres viajes a Sicilia, la primera vez para ver la isla y los cráteres del Etna: En esta ocasión Dionisio, el hijo de Hermócrates, estando en el trono, lo obligo a intimar con él. Pero cuando Platón se enfrentó a la tiranía y sostuvo que el interés del gobernante no era sólo lo mejor, a menos que también fueran destacado en la virtud. Él ofendió a Dionisio, quien en su ira exclamó: "Tú hablas como un viejo". "Y tú pareces un tirano", replicó Platón. En esta oportunidad, el tirano entró en furia y, en un principio, tuvo propensión en darle muerte; luego, cuando él había sido disuadido de esto por Dion y Aristómenes, no fue verdaderamente tan lejos, pero lo entregó a Pollis, el Lacedemonio, quien justo en ese momento había llegado con una embajada, con órdenes de venderlo a la esclavitud. ${ }^{4}$ (Diogenes Laertius, 1959, p. 293)

Tal como se puede leer, Platón tuvo algunos inconvenientes en esta isla y pasó por algunas humillaciones, de las cuales los historiadores mencionan algunas, pero obvian otras, por ejemplo, aunque la de intimar con alguien del mismo sexo no era para la cultura griega una humillación, todo lo contrario era el ser obligado a intimar ya que la obligación impide la libertad de acción o elección y, según cuenta la narración, el suceso desagradable para Platón ocurrió después de ser obligado a tener esta intimidad. Consecuencia de ello, devino la degradación más grande que puede tener cualquier ciudadano griego u hombre libre y, en este caso, este filósofo la tuvo al ser detenido y vendido como esclavo en la plaza pública: "Y Pollis se lo llevó a Egina y ahí lo ofreció a la venta... La asamblea decidió no darle muerte, pero que lo vendan como si fuera un prisionero de guerra"5 (Diogenes Laertius, 1959, p. 295), por veinte o treinta minas, según la tradición escrita que ha llegado a la actualidad: "Anniceris de Cirene estaba casualmente presente y lo rescató por veinte minas — según otros, la suma fue de treinta minas-y lo envió a Atenas a sus amigos, quienes de inmediato devolvieron el dinero"6 (Diogenes Laertius, p. 295), aunque al final fuera rescatado por sus discípulos. 
A pesar de este inconveniente, Platón insistió en sus viajes a Sicilia. Un ejemplo de esto fue el segundo viaje, donde los registros cuentan que pasó gran peligro:

La segunda vez él visitó al joven Dionisio, solicitando de él tierras y pobladores para la realización de su república. Dionisio les prometió, pero no cumplió su palabra. Algunos dicen que Platón estuvo también en gran peligro, siendo sospechoso de animar a Dion y Theodotas en un plan para liberar la isla entera. En esta ocasión, Arquitas, el Pitagórico, escribió a Dionisio, procuró su perdón y le obtuvo una escolta segura hacia Atenas. ${ }^{7}$ (Diogenes Laertius, 1959, p. 297)

Se observa en este viaje que Platón quiso realizar un ideal político: fundar una república, pero no se pudo concretar por las promesas incumplidas. A pesar de la frustración y los peligros existentes, considerando el desenlace del primer viaje, Platón no desistió y continuó con sus proyectos.

En su tercer viaje, la situación y los planes de Platón para ejecutar su ideal de república en tierras lejanas a su lugar de nacimiento siguió siendo estéril:

La tercera vez él llegó para reconciliarse con Dion y Dionisio, pero sin poder hacerlo, regresó a su país sin lograr nada. Y allí él se abstuvo de entrometerse con políticos, aunque sus escritos demuestran que fue un estadista. La razón era que las personas ya habían estado acostumbradas a las medidas e instituciones completamente diferentes de sí mismo. ${ }^{8}$ (Diogenes Laertius, 1959, p. 297)

En resumen, se puede afirmar acerca de Platón que provino de un hogar aristocrático, viajó a servir (léase ahora: asesorar) al rey de Siracusa, pero no le fue bien, fue forzado a tener intimidad, acusado de conspiración, perseguido, deportado, encarcelado, encadenado y sufrido la más vil de todas las humillaciones de su época: la esclavitud. Fue vendido como esclavo (387 antes de n. e.); sin embargo, sacó lección de las adversidades y puso su propia escuela, la Academia, donde enseñó y continuó su labor educativa, luego de que recuperara su libertad. Al respecto, existe la siguiente información:

La enseñanza de Sócrates y su alta ejemplaridad moral hallaron un cauce definitivo en la Academia, fundada por Platón (387). No deja de ser una tradición la que relaciona el hecho con el lance ocurrido al filósofo en Egina. Según ella, el dinero que había de servir a su rescate, rechazado por los eginetas, que identificaron la personalidad del prisionero, fué [sic] destinado íntegramente a la creación de la famosa escuela de Atenas, cuyo nombre de Academia deriva de Academos, dueño del gimnasio donde fue erigida. (Anónimo, 1965, p. XVII) 
Con respecto a lo mencionado sobre Platón, Luis Benites (2001) ha sostenido que la resiliencia es una capacidad de recuperarse rápidamente después de haber sido forzado, lastimado o presionado. Esta capacidad se ve representada en la vida de Platón, sobre todo, después de sus tres estancias en Siracusa. Por ende, cuando Benites (2001) vuelve a señalar que la resiliencia es la capacidad natural de las personas para resistir, afrontar y superar condiciones de riesgo y levantarse después situaciones adversas, se puede apreciar que todas estas capacidades estuvieron presentes en Platón por las circunstancias vivenciales difíciles y extremas por las que tuvo que pasar y sobresalir. Esta característica de cómo hacer resiliencia es abordada desde otra perspectiva, también, cuando se buscan soluciones positivas ante los encuentros negativos y se persiste en ello: "cierta capacidad humana para dar una respuesta afirmativa a diversas condiciones materiales y subjetivas adversas que le ha tocado vivir" (Chamochumbi, 2005, p. 1).

\section{La resiliencia en Aristóteles}

Otra muestra de resiliencia es la vida de Aristóteles (384-322 antes de n. e.) cuando supo enfrentar una situación difícil en su vida al saber que el quehacer filosófico de su época se había trasladado a Atenas y que fuera de ella no podía tener éxito, se trasladó a esta polis griega a estudiar en la Academia de Platón - la más grande escuela de filosofía junto al más grande maestro de filosofía en ese momento - donde destacó como un buen discípulo. Acerca de sus orígenes, Diógenes de Laercio afirmó lo siguiente:

Aristóteles, hijo de Nicómaco y Faestis, era un nativo de Estagira. Su padre, Nicómaco, como Hermipo se refiere en su libro Sobre Aristóteles, rastreó la descendencia de Nicómaco quien fuera hijo de Machaon y nieto de Euscalapio; allí residió con Amyntias, el rey de Macedonia, en la condición de médico y amigo. Aristóteles fue el discípulo más auténtico de Platón...9 (Diogenes Laertius, 1959, p. 445)

Como se puede prestar atención, Aristóteles nació en Estagira, un pequeño poblado bajo la égida de Filipo de Macedonia y, aunque no fue un noble tampoco era de origen humilde. Su padre fue un médico de la corte macedónica, lo cual le permitió viajar a Atenas a estudiar filosofía; sin embargo, su situación no era muy cómoda en esta gran ciudad ya que cuando se encontraba estudiando en la escuela de Platón y destacando, como dicen los escritos, como el más insigne de los discípulos, no tuvo la oportunidad de dirigir la Academia por un sencillo obstáculo: él era un meteco en Atenas, es decir, un extranjero, y como todo extranjero no tenía la más mínima oportunidad de dirigir una escuela en la ciudad de los más grandes pensadores y, menos, aún, tener una propiedad 
dentro de los muros de ella, por ende, decidió independizarse de su maestro. Parte de esta historia es narrada por Diógenes de Laercio:

Él se separó de la Academia cuando Platón aún estaba vivo. Por lo tanto, la observación atribuida a este último: "Aristóteles me menosprecia, como los potros patean a la madre, quien se aburre de ellos". Hermippo en sus Vidas menciona que él estuvo ausente de Atenas, enviado a la corte del rey Filipo, cuando Xenócrates se convirtió en la cabeza de la Academia, y que, a su regreso, cuando vio a la escuela bajo su nuevo jefe, él hizo elección de un camino público en el Liceo donde discutiría filosofía caminando hacia arriba y hacia abajo con sus discípulos hasta que llegaba la hora de frotarse con el aceite ellos mismos. De ahí el nombre "Peripatético". Pero otros dicen que este nombre fue dado a él porque, cuando Alejandro se estaba recuperando de una enfermedad y hacía sus caminatas diarias, Aristóteles se unía a él y conversaban sobre ciertos asuntos. ${ }^{10}$ (Diogenes Laertius, 1959, pp. 445 y 447)

Se puede notar que la situación de Aristóteles es adversa como se le viese. Tiene todo para perder y no realizar su proyecto de vida: comienza a estudiar filosofía un poco tarde — no es joven - y es ajeno o extranjero en Atenas, por ende, no puede ser ciudadano ateniense ni dirigir la Academia de Platón. Ante la elección de su maestro, la solución no fue difícil, un discípulo tuvo la iniciativa o por orden de él de alquilar un local en las afueras de la ciudad donde fundó el Liceo (335 antes de n. e.) y pudo concretar sus proyectos:

Aristóteles regresa a Atenas el 335, a los 50 años de edad y a los 13 de haber salido de ella, e inicia la tercera fase de su vida fundando su propia escuela, el Liceo, que no destinará, como la Academia, a la investigación de la matemática y la dialéctica, sino a unas investigaciones de carácter más amplio relacionadas con la ciencia de la naturaleza. Como meteco que es, no puede adquirir terrenos y se instala en un pórtico largo de un gimnasio público, fuera de las murallas, junto a un santuario dedicado a Apolo Licio (Apóllon Lýkeion). El nombre en griego de pórtico, perípatos, por un lado, y el del héroe del santuario, por otro, ha dado origen a las dos denominaciones con que históricamente se conoce a la escuela de Aristóteles: el Liceo y el Perípato. Permaneció al frente de su Escuela hasta la muerte de Alejandro Magno, ocurrida a sus 32 años, mientras esperaba conquistar Arabia. (Cortés y Martínez,

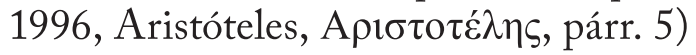

En pocas palabras, se puede observar aquí que, ante la adversidad, Aristóteles no se amilanó, por el contrario, trabajó para elaborar o construir su propio centro de enseñanza sin resignarse a los designios de los dioses ni a las leyes de las polis que como sistema político ya se encontraba en crisis en ese momento. 


\section{La resiliencia en Cleantes}

El último ejemplo de resiliencia y, tal vez, el más notable que se presenta en este artículo es el de Cleantes (331-231 antes de n. e.). Este filósofo nació en Assos, tuvo un origen humilde - pobre como Sócrates - y llegó a Atenas - meteco como Aristóteles - con pocas monedas. Luego, trabajó duro en lo que pudo para poder realizar su proyecto de vida que solo era estudiar filosofía:

Cleantes, hijo de Fania, fue nativo de Assos. Este hombre, dijo Antístenes en sus Sucesiones de filósofos, fue primero un pugilista. Él llegó a Atenas, como dice la gente, con sólo cuatro dracmas; reuniéndose con Zenón, estudió filosofía de manera noble y se adhirió a las mismas doctrinas en todo. Fue célebre por su industria, siendo de hecho impulsado por la extrema pobreza trabajar para ganarse la vida. Así, mientras que por la noche él se empleó para jalar agua a los jardines, por la mañana, se ejercitó a sí mismo en los argumentos; de ahí el sobrenombre de Phreantles o Buen-levantador que le fue dado. Él ha dicho que había sido llevado a los tribunales para responder a la pregunta: ¿cómo un tipo tan fuerte se ganaba la vida?, y luego de haber sido absuelto de presentar como sus testigos al jardinero en cuyo jardín él echó el agua y a la mujer que le vendió la comida, la cual utilizó para estrujar. ${ }^{11}$ (Diogenes Laertius, 1958, p. 273)

Ya ha sido informado que el trabajo o esfuerzo físico no era bien visto en la enseñanza de la filosofía, inclusive en el todo el mundo griego, tal es el caso de Cleantes quien se encuentra en esta situación, al extremo de incumplir otra observación que no era bien recibida por los círculos filosóficos de la época: Cleantes llegó a recibir limosnas en algunas ocasiones, de las cuales en la primera oportunidad fue obligado a no aceptar el óbolo por parte de su maestro: "Los Areopagitas estuvieron satisfechos y le dieron una donación de diez minas que Zenón le prohibió aceptar. También se nos dijo que Antígona le hizo un presente de tres mil dracmas"12 (Diogenes Laertius, 1958, pp. 273 y 275).

Estas facetas de su vida, donde tratan de burlarse de su condición humilde y la necesidad de trabajar para ganarse la vida, realizando una serie de trabajos manuales, para poder pagar sus estudios de filosofía, son recordadas en el siguiente párrafo:

Hay otra historia de Antígona cuando atendiendo a sus clases preguntó sobre él: ¿por qué él cargaba agua?, y recibió la repuesta: “¿Estar cargando agua es todo lo que yo hago? ¿Qué? ¿Acaso no lo entiendo yo? ¿Qué? ¿Acaso no riego el jardín?, o ¿acaso no emprendo alguna otra labor por amor a la filosofía?" Porque Zenón acostumbraba a disciplinarlo por esto y darle un óbolo como su salario. Y un día él produjo un puñado de pequeñas monedas ante su conocimiento y dijo: "Cleantes incluso podría mantener un segundo Cleantes, si él quisiera, mientras que aque- 
llos que poseen los medios para mantenerse a sí mismos, sin embargo, prefieren vivir a expensas de otros y eso también porque tenía bastante tiempo libre para sus estudios". De aquí que Cleantes fue llamado un segundo Hércules. Tenía ingenio, pero no una natural aptitud para la física, y fue exageradamente lento. ${ }^{13}$ (Diogenes Laertius, 1958, p. 275)

Tal fue la vida de Cleantes, llegando a ser blanco de todo tipo de ironías, del desprecio de las personas, de la sorna de sus contemporáneos, de los insultos que han quedado acuñados en la historia de la filosofía:

Sobre lo cual cuenta Timón, lo describe así: quién es éste que parece un campo de campana de carneros sobre las filas de los hombres, un estúpido, un amante del verso, oriundo de Assos, una masa de roca, un desventurado"14 (Diogenes Laertius, 1958, p. 275).

El trabajo manual, es decir, el trabajo duro con el cual se ganó la vida con el sudor de su frente y con la espalda siempre mojada, sea de sudor o agua, fue una característica singular en la vida de Cleantes. Este filósofo rompió la tradición que hasta la época se tenía de los pensadores que solo teorizaban y se alejaban del esfuerzo físico para poder vivir, se apartó de los estereotipos que el filósofo solo vive de sus rentas y, a pesar de las ofensas que recibió, él continuó con su quehacer diario hasta conseguir sus objetivos:

Una vez, cuando fue reprochado por cobardía, contestó: "Eso es porque así rara vez yo voy mal". Otra vez, cuando le ensalzaban su manera de vivir sobre ser acaudalado, él empleó decirles que mientras ellos estaban jugando con el balón, él estaba en el trabajo cavando la tierra dura y yerma. ${ }^{15}$ (Diogenes Laertius, 1958, p. 277)

Incluso, soportando las burlas de sus compañeros: "Y él lo empleó para soportar el sarcasmo de sus compañeros y no se preocupó que fuera llamado burro, les respondió que él sólo era bastante vigoroso para llevar la carga de Zenón"16 (Diogenes Laertius, 1958, pp. 275 y 277), pero a pesar de las burlas, ofensas y todo tipo de situaciones adversas como los contratiempos surgidos por falta de dinero o las tradiciones de los atenienses, Cleantes se supo sobreponer no solo para estudiar sino también para llegar más lejos. Al final, esta actitud y su desempeño como estudiante lo llevaron a ser reconocido por su maestro hasta llegar a nombrarlo como su sucesor: "Tal fue él y todavía aunque Zenón tuvo muchos otros discípulos eminentes, él fue calificado para sucederlo en la dirección de la escuela"17 (Diogenes Laertius, pp. 275 y 277). En este caso, se puede observar que Cleantes tuvo mejor suerte que Aristóteles ya que puedo heredar la dirección de la escuela de su maestro.

Con respecto al tema de la resiliencia, la vida de este pensador fue, particularmente, más significativa que las anteriores que se han mencionado porque se 
presentan situaciones extremas que pudieron impedirle realizar sus más encarecidos sueños, sin embargo, los superó todos. Se pueden observar situaciones comunes y diferencias específicas, por ejemplo, con Sócrates y Aristóteles. Es notoria su semejanza con Sócrates. Al igual que el ateniense, venía de un origen humilde y no tenía dinero, pero lograron realizar sus ideales relacionados con la filosofía, aunque, por otro lado, había una pequeña diferencia entre los dos, Cleantes la tenía más difícil ya que era extranjero y solo quería estudiar filosofía, Sócrates era ateniense y quería enseñarla. Al final, los dos lograron sus objetivos, sólo que Cleantes fue más allá: logró enseñar en una escuela filosófica. Por otro lado, con Aristóteles tenía también cosas comunes: los dos querían estudiar filosofía y lo lograron a pesar de ser metecos, es decir, extranjeros en Atenas y, por lo tanto, no podían poseer predios en la ciudad. Además, los dos pudieron enseñar filosofía, pero aquí surge la diferencia entre los dos, Aristóteles tuvo que crear su escuela, mientras que Cleantes dirigió la escuela donde estudió. Esta diferencia lo llevó a ser reconocido por la historia de la filosofía como: "Cleantes de Assos, el inmediato sucesor de Zenón" (Russell, 1971, p. 282), quien tuvo serios inconvenientes económicos para estudiar filosofía, decidió alquilarse como mozo de cuerdas en Atenas, es decir, ganaba un poco de dinero como estibador para poder pagar sus estudios en la escuela de Zenón, el estoico, llegando a terminar y ser, incluso, el heredero de su maestro.

Como se ha mencionado antes, en la Grecia clásica hubo un enorme desprecio por el trabajo manual, considerado de menor valía frente a la actividad especulativa, sin embargo, Cleantes superó todos estos prejuicios para cumplir su proyecto de vida que no era otro que el de estudiar y aprender filosofía en una escuela hasta llegar a dirigirla. Tales son las situaciones o anécdotas en la vida de Cleantes que se pueden observar y se puede, también, percibir como las características más significativas de la resiliencia enunciados por Boris Cyrulnik (2005), Kotliarenco et al. (1997) y Chamochumbi (2005) se cumplen totalmente.

\section{Conclusión}

En síntesis, se llegan aquí a tres conclusiones sobre la resiliencia en la que se hace referencia al significado del término y donde se hace una aplicación del mismo en la filosofía o historia de la filosofía.

En la primera se puede evidenciar que existe un enfoque antitético —dos sentidos del término, el positivo y el negativo- de la resiliencia en la psicología. Aparece el sentido positivo cuando la resiliencia está ligada a la capacidad del ser humano para enfrentar adversidades y surge el sentido negativo cuando se observa que el término en cuestión pretende alcanzar el estatus de técnico, pero no lo logra ya que su uso solo se encuentra en el lenguaje ordinario y 
significa muchas cosas a la vez. Esta manera de ver a la resiliencia constituye una fortaleza y debilidad a la vez, ya que la relación de rechazo y atracción que guardan los significados hace atractivo y posible el uso del término en distintas disciplinas, entre ellas, la filosofía.

En la segunda, se puede afirmar dentro de una interpretación y expresión libre que la resiliencia es la capacidad de "hacer de tripas, corazón", es decir, es la facultad que tiene todo ser humano para superar la adversidad y salir airoso ante las circunstancias desfavorables. Claro está que para que haya resiliencia, las personas tienen que estar primero en las situaciones límites para salir de ellas por sí solas y no solamente salir de ellas. De este modo, y tomando las licencias respectivas, en este texto se han dado cinco ejemplos de resiliencia en la vida y actividad de personajes de la filosofía griega, aclarando que, aunque es un término nuevo dentro de esta disciplina, aparecen características, significados o definiciones de este concepto cuando se examina la vida de los personajes mencionados donde se expresan las capacidades humanas y la fuerza de voluntad por superar las situaciones límites.

Por último, aun cuando sean pocas las personas que se preocupan por la resiliencia y, menos aún, sean los ejemplos en el campo de la actividad filosófica, se espera que el análisis de la vida de estos filósofos que fueron tomadas como paradigmas de resiliencia sirvan de motivación no solo para aquellos que se interesan en la filosofía, su historia y su enseñanza, sino también para las personas comunes y corrientes en las situaciones cotidianas de la vida, por ende, hay que recordar que la resiliencia puede aplicarla cualquier persona.

\section{Notas}

1 Traducción libre del inglés al castellano desde aquí hacia adelante: Hieronymus of Rhodes in the second book of his Scattered Notes relates that, in order to show how easy it is to grow season for olives, rented all the oil-mills and thus amassed a fortune.

2 Socrates was the son of Sophroniscus, a sculptor, and Phaenarete, a midwife, as we read in the Theaetetus of Plato; he was a citizen of Athens y belonged to the deme Alopece.

3 Plato was the son of Ariston and a citizen of Athens. His mother was Perictione (or Potone), who traced back her descent to Solon.

$4 \mathrm{He}$ made three voyages to Sicily, the first time to see the island and the craters of Etna: on this occasion Dionysius, the son of Hermocrates, being on the throne, forced him to become intimate with him. But when Plato held forth on tyranny and maintained that the interest of then ruler alone was not the best end, unless he were also pre-eminent in virtue, he offended Dionysius, who in his anger exclaimed, "You talk like an old dotard." "And you like a tyrant," rejoined Plato. At this the tyrant grew furious and at first was bent on putting him to death; then, when he had been dissuaded from this by Dion and Aristomenes, he did not indeed go so far but handed him over to Pollis the Lacedaemonian, who had just then arrived on an embassy, with orders to sell him into slavery. 
5 And Pollis took him to Aegina and there offered him for sale.... The assembly decided not put him to death but to sell him just as if he were a prisoner of war.

6 Anniceris the Cyrenaic happened to be present and ransomed him for twenty minae - according to others the sum was thirty minae- and dispatched him Athens to his friends, who immediately remitted the money.

7 The second time he visited the younger Dionysius, requesting of him lands and settlers for the realization of his republic. Dionysius promised them but did not keep his word. Some say that Plato was also in great danger, being suspected of encouraging Dion and Theodotas in a scheme for liberating the whole island; on this occasion Archytas the Pythagoream wrote to Dionysius, procured his pardon, and got him convoyed safe to Athens.

8 The third time he came to reconcile Dion and Dionysius, but, failing to do so, returned to his own country without achieving anything. And there he refrained from meddling with politics, although his writings show that he was a statesman. The reason was that the people had already been accustomed to measures and institutions quite different from his own.

9 Aristotle, son of Nicomachus and Phaestis, was a native of Stagira. His father, Nicomachus, as Hermippus relates in his book On Aristotle, traced his descent from Nicomachus who was the son of Machaon and grandson of Asclepius; and he resided with Amyntas, the king of Macedon, in the capacity of physician and friend. Aristotle was Plato's most genuine disciple...

$10 \mathrm{He}$ seceded from the Academy while Plato was still alive. Hence the remark attributed to the latter: "Aristotle spurns me, as colts kick out at the mother who bore them." Hermippus in this Lives mentions that he was absent as Athenian envoy at the court of Philip when Xenocrates became head of the Academy, and that on his return, when he saw the school under a new head, he made choice of public walk in the Lyceum where he would walk up and down discussing philosophy with his pupils until it was time to rub themselves with oil. Hence the name "Peripatetic." But others say that it was given to him because, when Alexander was recovering from an illness and taking daily walks, Aristotle joined him and talked with him on certain matters.

11 Cleanthes, son of Phanias, was a native of Assos. This man, says Antisthenes in his Successions of Philosophers, was at first a pugilist. He arrived in Athens, as people say, with four drachmas only, meeting with Zeno he studied philosophy right nobly and adhered to the same doctrines throughout. He was renowned for his industry, being indeed driven by extreme poverty to work for a living. Thus, while by night he used to draw water in gardens, by day he exercised himself in arguments: hence the nickmaname Phreantles or Well-lifter was given him. He is said to have been brought into court to answer the inquiry how so sturdy a fellow as he made his living, and then to have been acquitted on producing as his witnesses the gardener in whose garden he drew water and the woman who sold the meal which he used to crush.

12 The Areopagites were satisfied and voted him a donation of ten minas, which Zeno forbade him to accept. We are also told that Antigonus made him a present of three thousand drachmas.

13 There is another story that Antigonus when attending his lectures inquired of him why he drew water and received the reply, "Is drawing water all I do? What? Do I not dig? What? Do I not water the garden? or undertake any other labour for the love of philosophy?" For Zeno used to discipline him to this and bid him return him an obol from his wages. And one day he produced a handful of small coin before his acquaintance and said, "Cleanthes could even maintain a second Cleanthes, if he liked, whereas those who possess the means 
to keep themselves yet seek to live at the expense of others, and that too though they have plenty of time to spare from their studies." Hence Cleanthes was called a second Heracles. He had industry, but no natural aptitude for physics, and was extraordinarily slow.

14 On which account Timon describes him thus: Who is this that like a bell-wether ranges over the ranks of men. A dullard, lover of verse, hailing from Assos, a mass of rock, unventuresome.

15 Once when he was reproached with cowardice, he replied, "That is why I so seldom go wrong." Again, when extolling his own manner of life above that of the wealthy, he used to say that, while they were playing at ball, he was at work digging hard and barren ground.

16 And he used to put up with gibes from his fellow-pupils and did not mind being called the ass, telling them that he alone was strong enough to carry the load of Zeno.

17 Such was he; and yet, although Zeno had many other eminent disciples, he was able to succeed him in the headship of the school.

\section{Referencia}

Aristófanes. (1957). Comedias completas: Los acarnienses, los caballeros, las nubes, las avispas y la paz. (Vol. 1). Buenos Aires: El Ateneo.

Aristóteles. (1976). Extractos de la Política. En Reyes, A., Romero, F., De Onís, F. Baeza, R. y Arciniegas, G. (Eds.), Obras filosóficas: Metafísica, Ética, Política, Poética, (7a ed.), 259-346. Buenos Aires: El Ateneo.

Anónimo. (1965). Platón (428-347). En Platón. Diálogos: la República o el Estado (pp. XV-XXIV). Madrid: EDAF.

Benites, L. A. (2001). Resiliencia y educación. En Revista Peruana de Psicología, 11, 21- 25 .

Cortés Morató,J. \& Martínez Riu, A. (1996). Diccionario de filosofía en CD-ROM. Copyright. Barcelona: Empresa Editorial Herder S.A

Cyrulnik, B. (2005). Los patitos feos. La resiliencia: una infancia infeliz no determina la vida. Barcelona: Editorial Gedisa, S. A.

Cyrulnik, B. \& Seron, C. (2003). La résilience ou comment renaître de sa souffrance. Paris: Éditions Fabert, de https://www.youscribe.com/BookReader/In$\operatorname{dex} / 2450540 /$ ?documentId $=2427597$

Chamochumbi, W. (2005). La resiliencia en el desarrollo sostenible: algunas consideraciones teóricas en el campo social y ambiental, de https://agua.org.mx/ wp-content/uploads/filespdf/doc_pdf_5707.pdf

Diccionario latino-español español-latino. (1958). Barcelona: Editorial Dalmau y Jover S.A.

Diogenes Laertius. (1959). Lives of eminent philosophers. (Vol. 1). London. William Heinemann Ltd.

Diogenes Laertius. (1958). Lives of eminent philosophers. (Vol.2). London. William 
Heinemann Ltd.

Jaeger. W. (2010). Paidea: los ideales de la cultura griega. México: FCE.

Kotliarenco, M., Cáceres, I. y Fontecilla, M. (1997). Estado de arte en resiliencia. Organización Panamericana de la Salud, Oficina Sanitaria Panamericana, Oficina Regional de la Organización Mundial de la Salud. Fundación W. K. Kellogg. Agencia Sueca de Cooperación Internacional para el Desarrollo. Centro de Estudios y Atención del Niño y la Mujer (CEANIM).

Los filósofos presocráticos (Vol. 1). (2001). Madrid: Gredos.

Melillo, A. (2004). Resiliencia. En Asociación Escuela Argentina de Psicoterapia para Graduados (compilador). Revista "Psicoanálisis: ayer y hoy", 1, http:// www.elpsicoanalisis.org.ar/old/impnumero1/resiliencia1-doc.htm

Piña, J. (2015). Un análisis crítico del concepto de resiliencia en psicología. En Universidad de Murcia, Anales de psicología, 31, (751-758). Murcia, España: Servicios de Publicaciones de la Universidad de Murcia http://dx.doi. Org/10.6018/analesps.31.3.185631

Platón. (1965). Diálogos: la República o el Estado. Madrid: EDAF.

Platón. (1975). Teeteto-Gorgias. Lima: Universo.

Russell, B. (1971). Historia de la filosofía occidental (Vol. 1). Madrid: Espasa Calpe. 
